\title{
Proposta de conteúdos alternativos e atividades para abordagem do tema água no ensino médio
}

\author{
Claudia de Vilhena Schayer Sabino \\ Progr. Pós-Grad. Ensino de Ciências e \\ Matemática, PUC-Minas, Belo Horizonte, MG. \\ sabinoc@pucminas.br \\ Wolney Lobato \\ Progr. Pós-Grad. Ensino de Ciências e \\ Matemática, PUC-Minas, Belo Horizonte, MG. \\ Fernando Costa Amaral \\ Progr. Pós-Grad. Ensino de Ciências e \\ Matemática, PUC-Minas, Belo Horizonte, \\ MG.Isabela Moreira \\ Mestranda do Progr. Pós-Grad. Ensino de \\ Ciências e Matemática, PUC-Minas, Belo \\ Horizonte, MG.
}

\begin{abstract}
ALTERNATIVE TOPICS AND ACTIVITIES FOR THE WATER STUDY IN THE MIDDLE SCHOOL. All life as we know depends strictly on water. as a mythic component is present in religions, traditions and legends, revealing that human culture has always recognized the importance of this natural resource as vital to the maintenance of life and necessary for various socio-cultural and economic activities. Despite the abundance of water on the planet, many countries develop conflicts due to scarcity of the precious liquid. This situation has been exacerbated by population growth and by various human activities. Abusive or unreasonable use, as well as contamination by domestic sewage, agricultural, industrial and mining activities have compromised, increasingly, the quantity and quality of water sources on the planet. Recognizing education as fundamental to the rescue of awareness and sense of respect for the water, able to promote the protection and conservation of water resources, in this work we present a proposal for the content and activities to address the water issue in high school, with approaches in science, Technology, Society and Environment (STSE).Citation : Sabino C.V.S., Lobato W., Amaral F.C. 2014. Proposta de conteúdos e atividades para abordagem do tema água no ensino médio. Terræ Didatica, 10(3):407-424. http:// www.ige.unicamp.br/terraedidatica/.
\end{abstract}

KEYWORDS: Water, environment, educational activities, CTSA approach.

RESUMO Toda vida que conhecemos depende estritamente da água. A água como componente mítico está presente nas religiōes, lendas e tradições, revelando que a cultura humana sempre reconheceu a importância deste recurso natural como indispensável para a manutenção da vida e necessária para diversas atividades socioculturais e econômicas. Apesar da abundância de água no planeta, vários países vivenciam conflitos devido à escassez do precioso líquido. Esta situação tem sido agravada pelo crescimento populacional e por diversas atividades antrópicas. A utilização abusiva e irracional, bem como a contaminação por esgotos domésticos, atividades agropecuárias, industriais e de extração mineral têm comprometido, de forma crescente, a quantidade e a qualidade de mananciais hídricos do Planeta. Reconhecendo a educação como fundamental para a conscientização e resgate do sentimento de respeito pela água, capaz de promover a proteção e conservação dos recursos hídricos, apresentamos nesse trabalho uma proposta de conteúdos e atividades para a abordagem do tema água no ensino médio, com enfoques em Ciência, Tecnologia, Sociedade e Ambiente (CTSA).

PALAVRAS CHAVE: Água, meio ambiente, atividades didático-pedagógicas, enfoque CTSA. 


\section{Introdução}

Desde os primórdios da humanidade o elo entre as pessoas e a água é tanto instintivo quanto intencional, regido por não só necessidades pessoais e coletivas, mas por sentimentos de respeito e fascínio. Por mais descrente e materialista que sejamos, normalmente nos sentimos emocionados e deslumbrados com a beleza e, por que não dizer, espiritualidade de uma praia deserta, de uma cachoeira perdida na floresta ou de um riacho cristalino e murmurante rolando entre as pedras. A "Hipótese da Biofilia” defendida por Wilson (1984) sugere que há um vínculo instintivo entre os seres humanos e a natureza. A água possui uma estreita relação com a manutenção e a exuberância de sistemas vivos naturais, e a valorização de alguns aspectos simbólicos relacionados ao tema, presentes em algumas das atividades desenvolvidas, tem a intenção de favorecer não só o processo de ensino-aprendizado, como a possível formação de hábitos e atitudes.

Salientamos que não estamos aqui defendendo a apreciação estética da natureza nem pretendemos instigar preocupações de caráter puramente ético. Sabemos que é preciso equacionar as demandas socioeconômicas e ambientais do mundo atual em consonância com a conservação da natureza e preservação da biodiversidade. No entanto acreditamos que a educação é mais efetiva quando a afetividade é despertada ou estimulada em docentes e discentes.

Escolhemos a abordagem CTSA (Ciências, Tecnologias, Sociedade e Ambiente), por acreditarmos, como Ricardo (2007), que tal abordagem configura-se como uma estratégia de ensino que se caracteriza por aproximar o conteúdo didático das práticas sociais, visando a formação de cidadãos críticos a atuantes, conscientes de que a Ciência e a Tecnologia são ferramentas que devem estar a serviço do desenvolvimento da sociedade e não ao contrário. Segundo Silva et al. (2002) os temas relacionados às abordagens CTSA são caracterizados por afetar a vida das pessoas em várias partes do mundo e por não serem passíveis de compreensão ou tratamento adequado somente em contexto local ou nacional. Ríos e Solbes (2007) afirmam que essas abordagens, embora necessárias, praticamente não são ainda significativamente utilizadas em cursos superiores, ou na formação continuada de professores.

O uso dessas abordagens, segundo Fontes e Cardoso (2006), se justifica, pois os benefícios introduzidos nas aulas de ciências são reais e con- sistentes, uma vez que, entre outras coisas, aumentam a literacia científica dos alunos, promovem o interesse pela ciência e ajudam a melhorar o espírito crítico, o pensamento lógico e a tomada de decisão.

A problemática atual relacionado à água constitui um tema tipicamente CTSA, que por um lado aborda como a ciência e a tecnologia podem responder à demandas e auxiliar na solução problemas ambientais mas, por outro lado, pode agravá-los direta ou indiretamente ao "criar necessidades" pessoais e coletivas com consequências para o equilíbrio ambiental e para a saúde. A ciência e a tecnologia têm interferido no ambiente e suas aplicações são objeto de muitos debates éticos, o que torna inconcebível a ideia de uma ciência pela ciência, sem consideração de seus efeitos e aplicações (Santos e Cardoso 2002).

O presente trabalho apresenta algumas atividades relacionadas ao tema água, aplicadas a um curso de formação de professores do ensino médio em rede, e à distância, na área de Meio Ambiente, bem como em encontro presencial, em 2013, no qual estavam presentes 52 professores do ensino médio. O curso faz parte de um projeto da Secretaria de Educação do Estado de Minas Gerais (SEEMG), que atenta às peculiaridades do mundo contemporâneo criou o projeto Reinventado o Ensino Médio (REM), idealizado em 2011, com o intuito de repensar o currículo do Ensino Médio nas escolas estaduais mineiras. $\mathrm{O}$ projeto busca reformular o Ensino Médio, reconstruindo sua identidade como última etapa da Educação Básica, por meio de uma ordenação curricular e estratégias didático-pedagógicas inovadoras que estabeleçam uma efetiva relação com o conhecimento e possibilitem a construção da autonomia e da emancipação dos jovens, seja para a conclusão ou continuidade dos estudos ou para a preparação à inserção no mundo do trabalho (SEEMG 2013). Para o efetivo desenvolvimento do projeto foi necessário um curso de formação de professores em rede e a distância. Para isto professores da Rede Estadual de Ensino Médio participam de formação específica à distância em cada tema do projeto. Foram também promovidos alguns encontros presenciais e anuais, em Belo Horizonte, para os quais alguns professores das diferentes regiões de Minas Gerais foram convidados.

Se nos basearmos na universalidade e na efetividade das ações empreendidas até o momento constataremos que muito pouco tem sido feito no mundo para sanar definitivamente a problemática 
da água. A teoria de Maslow (1989) indica que a proteção e conservação dos recursos hídricos não são uma prioridade humana. No entanto, a conscientização e o resgate do sentimento de respeito pela água são indispensáveis para a sobrevivência da humanidade. Acreditamos que para a mudança desse quadro, o processo de ensino-aprendizagem desenvolvido em sala de aula ou em espaços não formais de ensino tenha um papel fundamental.

Dentre as estratégias utilizadas para a produção das atividades desenvolvidas destacamos a utilização da contextualização de conteúdos com temas da atualidade relacionados a água bem como pela utilização de dinâmicas e jogos como atividades lúdicas. Jovens e adultos se sentem motivados por atividades divertidas, competitivas e participativas, que muitas vezes são úteis para despertar o interesse e atenção. Alunos do turno da noite, cansados após uma jornada de trabalho se sentem motivados por atividades interativas (Oliveira 1999, Ricardo 2007).

Atividades lúdicas e jogos, no espaço escolar, não se justificam somente pelo estímulo ao aprendizado, podendo também contribuir de forma efetiva para a socialização dos alunos, educando-os para o respeito as diferença, para o trabalho em equipe, para o desenvolvimento da personalidade e da autoestima, ensinando tanto a valorizar o prazer do sucesso como saber conviver com frustrações. Exigem atenção às regras, como fica claro nesta passagem do livro "Os jogos e o lúdico na aprendizagem escolar":

"O jogar é o brincar em um contexto de regras e com um objetivo predefinido. Jogar certo, segundo certas regras e objetivos, diferencia-se de jogar bem, ou seja, da qualidade e do efeito das decisões e dos riscos. (...) O jogar é uma brincadeira organizada, convencional, com papéis e posições demarcadas. $\mathrm{O}$ que surpreende no jogar é o seu resultado ou certas reações dos jogadores. O que surpreende nas brincadeiras é sua própria composição ou realização. O jogo é uma brincadeira que evoluiu.(...)" (Macedo 2005)

Segundo Bovo (2002), a prática educativa de jovens e adultos "só terá realmente sentido quando for estimulada a desenvolver no educador e no educando o gosto de querer bem e de estar sempre alegre tanto nos momentos de ensinar como nos momentos de aprender."

A função da escola não apenas ensinar algumas dimensões relevantes do conhecimento humano, mas também educar para a cidadania, para o mundo do trabalho. $\mathrm{Na}$ escola o aluno deve aprender a aprender, aprender a interagir de uma forma saudável com os demais, aprender a ser e a poder se transformar.

Vivemos, hoje, um momento histórico de mudança de perspectiva familiar: o pai já não mais ocupa o lugar central, a separação é uma constante. Nos casos de separação, a mãe ou o pai do dissolvido casal que fica responsável pelos filhos, muitas vezes passa o dia fora de casa para assegurar o sustento da família. Não havendo a separação, o que se vê é, muitas vezes, a necessidade de ambos terem que passar o dia fora de casa para promover o sustento. Assim a Escola tem agregado o papel dos pais de ensinar às crianças, não o que pensar, mas como pensar. E nesse sentido o ensino que, além da transmissão de conhecimento e habilidades, agrega estratégias pedagógicas que favorecem a formação integral do cidadão. Aulas contendo jogos e outras dinâmicas de grupo voltadas para a aprendizagem atendem à demanda dos novos papéis assumidos pela escola.

"Hoje vemos muitos alunos desmotivados e desinteressados por aprender, mas podemos instigá-los usando jogos como desencadeadores, como despertadores de ações até mesmo não percebidas pelas crianças como possíveis de serem produzidas por si próprias.” (Macedo 2005, p.107)

Se antes na Escola o principal objetivo era assegurar o aprendizado dos conteúdos sistematizados, hoje, ela também tem como meta a formação cognitiva, afetiva e social do indivíduo. Tais transformações demandam grande diversidade de funções e ações, que dependem em grande parte da formação continuada de seus professores.

Maslow (1979) apresentou uma teoria da motivação, segundo a qual as necessidades humanas estão organizadas e dispostas em níveis, numa hierarquia de importância e de influência, que pode ser visualizada numa pirâmide. De acordo com este autor, as necessidades mais básicas, na base da pirâmide, são as fisiológicas: ar, água, alimento, abrigo, sexo, entre outras. Em seguida vêm a segurança e a estabilidade. Depois, as necessidades sociais: amor, afeto e amizade. Em seguida, necessidades de status e reconhecimento. Finalmente, no topo da pirâmide estão as necessidades de auto realização e contribuição para a sociedade.

Segundo o mesmo autor, as pessoas estão preocupadas em atender às necessidades, que se restringem ao tempo de vida de cada um. 
Dansereau (1999), em seu livro "Ecologia humana, ética e educação" salienta a relação entre a teoria de Maslow e os problemas ambientais. Os fenômenos naturais, muitas vezes, são lentos; algumas contaminações, por exemplo, demoram décadas até serem percebidas e a preocupação com estes fatos não está associada às necessidades humanas, tendo em vista o contraste de escala de tempo aí envolvido.

É importante então contextualizar a educação ambiental. Só protegemos o que conhecemos e se não estivermos conscientes do nosso envolvimento em uma problemática dificilmente ajudaremos a solucioná-la.

\section{Objetivos}

Embasado pelo referencial teórico apresentado, este trabalho tem como objetivo apresentar uma série de conteúdos desenvolvidos através de atividades didático-pedagógicas participativas e lúdicas utilizadas na abordagem do tema água, para a formação continuada de professores do ensino médio, visando aprimorar a prática docente no sentido despertar o interesse do aluno pelo conteúdo a ser trabalhado e favorecer interação entre professor/ aluno, aluno/conteúdo e aluno/aluno.

Foi com base no referencial teórico e em pesquisa bibliográfica sobre conteúdos e estratégias pedagógicas para o ensino da temática que elaboramos as atividades que hora apresentamos. Essas estratégias didático-pedagógicas foram testadas em encontro presencial com 52 professores do ensino médio de escolas públicas de diversas regiões de Minas Gerais e avaliadas através de questionário aplicado ao final dos trabalhos, e os resultados dessa avaliação também fazem parte do trabalho. Vale ressaltar que o trabalho aqui apresentado é parte de uma pesquisa mais ampla na qual investigamos metodologias inovadoras para o Curso "Recursos Naturais e Meio Ambiente" do Projeto "Reinventando o Ensino Médio", do Estado de Minas Gerais.

\section{Metodologia}

O primeiro passo da metodologia foi a realização de pesquisa bibliográfica para selecionar material. A bibliografia pesquisada é extensa e está listada no site: http://aguadeviver.wix.com/ inicio\#!bibliografia-consultada/c1mx6.

O livro texto, elaborado após a pesquisa biblio- gráfica e adotado foi "Água de beber, água de viver", disponível em: http://aguadeviver.wix.com/inicio. Este livro foi produzido com o apoio da Fundação de Amparo a Pesquisa do Estado de Minas Gerais (Fapemig) com o objetivo de colaborar na formação de professores do ensino médio e fundamental.

É vasta a literatura relacionada ao ensino/aprendizagem do conteúdo água no ensino fundamental e médio, mas tal bibliografia geralmente não é acessível para a maioria dos professores.

Um dos motivos para a dificuldade do acesso é a exclusão digital. Usualmente, a exclusão digital é descrita como uma metáfora para o problema do acesso desigual às Tecnologias de Informação e Comunicações (TIC’s) (Jung et al. 2001). A exclusão digital se constitui numa barreira que acaba por dividir a população em duas categorias: "os que têm" e "os que não têm". Deve ser lembrado que há uma diferença muito grande entre o simples "acesso" e o efetivo "uso". Enquanto "acesso" é um termo que simplesmente indica uma funcionalidade técnica ou relativa à infraestrutura, o termo "uso" é bem mais amplo, e se relaciona à capacidade de aplicação das TICs para se alcançar objetivos individuais ou coletivos (Gurstein 2003). Mesmo professores que têm acesso ao computador não conseguem selecionar material de qualidade que atenda às necessidades da sala de aula e aos interesses dos alunos. Outra dificuldade detectada é que geralmente os professores não dominam os idiomas inglês e/ou francês, o que dificulta o acesso a muitos materiais disponíveis na internet.

Uma excelente fonte de material didático é o site do USEPA (United States Environmental Protection Agency), disponível em (http://www. epa.gov/region1/students/teacher/groundw.html), o qual temos autorização legal para copiar, adaptar e modificar.

Após a pesquisa bibliográfica e leitura do material disponibilizado, foram selecionadas as atividades que mais se adequaram às condições brasileiras e principalmente mineiras. Estas foram traduzidas, adaptadas e testadas presencialmente com 52 professores participantes do projeto REM. Após a aplicação, a avaliação foi feita por meio de questionário semiestruturado.

Segundo Lima et al. (2009), por muito tempo o ato de ensinar resumiu-se em transmitir conteúdos, para alunos que se comportavam como agente passivo da aprendizagem e o professor único detentor do saber. Os recentes avanços tecnológicos, 
sociais e culturais provocaram mudanças profundas alterando o modo de viver e a leitura do mundo, com consequências nas relações interpessoais, como é o caso da prática docente. No bojo dessas mudanças a aula apenas expositiva tornou-se uma prática desmotivadora, que não aproveita recursos e estratégias pedagógicas capazes de estimular e promover e promover uma melhor aprendizagem de conteúdos, o desenvolvimento de habilidades promotora da socialização e da cidadania. Surgiu a necessidade de uma educação mais dinâmica e diversificada, na qual os alunos sejam desafiados e estimulados a buscarem o conhecimento de forma reflexiva e crítica.

Isso demonstra a importância de que sejam repensadas as atitudes e a forma de lidar com os conteúdos e também de conhecer melhor as características do desenvolvimento para que se possa propor situações de aprendizagem e apresentar conteúdos possíveis de serem compreendidos em extensão e profundidade.

As atividades e os jogos educativos são ótimos recursos que o professor pode utilizar, visto que proporcionam o desenvolvimento social do aluno, desde que estes não sejam usados como únicas ferramentas no processo de ensino aprendizagem. (Brougère 1998).

O uso dos jogos deve estar associado a outros recursos, pois a sua eficácia só ocorre quando o professor atua como orientador do processo. Sendo necessário um planejamento prévio por parte do professor para que os objetivos sejam bem definidos e que sejam alcançados no decorrer do processo. (Venancio 2005)

Segundo Vigotski (1998), neste contexto, o jogo torna-se um ótimo recurso de ensino para o professor no processo de ensino aprendizagem, por estimular o interesse do aluno, possibilitando a construção do conhecimento a partir de suas descobertas e da interação com os outros, pois os processos de desenvolvimento dos indivíduos estão relacionados com os processos de aprendizado adquiridos por meio da sua interação sociocultural.

Segundo Paulo Freire (1996) o jogo é uma coisa nova feita de coisas velhas. Quem vai ao jogo, leva, para jogar, as coisas que já possui que pertencem ao seu campo de conhecimento, que foram aprendidas anteriormente em procedimentos de adaptação, de suprimentos de necessidades objetivas. Os ingredientes do jogo, portanto, são as coisas velhas fechadas pela objetividade que marcou sua aprendizagem.

Os tópicos apresentados neste trabalho são compostos de uma aula teórica sobre o tema, seguida de atividades específicas que como sugerido por Cunha (2012) visam: a) apresentar um conteúdo programado; b) ilustrar aspectos relevantes de conteúdo; c) avaliar conteúdos já desenvolvidos; d) revisar e/ou sintetizar pontos ou conceitos importantes do conteúdo; e) destacar e organizar temas e assuntos relevantes do conteúdo; f) integrar assuntos e temas de forma interdisciplinar; g) contextualizar conhecimentos.

\section{Resultados}

\section{Atividades didático-pedagógicas - Produtos de pesquisa}

\subsection{Atividade I - Exemplo da importância da água na vida das pessoas}

Objetivos: Destacar alguns fatos relacionados à importância da água na vida das pessoas. Trabalho em equipe. Revisão de conceitos.

Materiais recomendados: $\mathrm{O}$ aluguel misterioso, Contas de água (solicitar aos alunos que tragam para escola).

Aspectos teóricos relacionados: Além de exercer forte apelo emocional sobre as pessoas, a água constitui parte integrante do organismo humano, sendo responsável por $75 \%$ de sua composição. Desempenha funções fisiológicas fundamentais, como: dissolver e diluir todos os componentes solúveis que entram no organismo ou que permanecem como constituintes celulares; ser veículo de transporte para elementos e compostos excretados; regular a temperatura corporal pelo processo de absorção de calor e de evaporação, através do processo contínuo de transpiração. Nenhum outro solvente apresenta, na temperatura e pressão normais, propriedades físicas, químicas e físico-químicas tão compatíveis com os processos biológicos essenciais (Porto 1991).

É também indispensável a diversas atividades humanas, como: irrigação, navegação, pesca, produção de energia, refrigeração de máquinas, processos industriais e construtivos, higiene e dispersão de rejeitos. 


\section{Atividades:}

- Promover uma "tempestade cerebral" sobre a importância da água na vida das pessoas. Anotar as sugestões dos alunos.

- Completar a lista de itens caso necessário.

- Explicar como é calculada a conta de água (PROCOM 2014). Perguntar aos alunos o valor da conta de água e quantas pessoas moram em sua casa. Perguntar e anotar os principais usos da água na casa de cada aluno. Anotar os valores comentar chamando atenção para usos não usuais, se ocorrerem, por exemplo: regar horta, lavar carros e outros.

- Ler o texto "O aluguel misterioso".

- Pedir aos alunos que, em grupo, discutam e respondam às perguntas apresentadas.

- Discutir os resultados.

O aluguel misterioso (Adaptado de Susan M. McMaster).

$\checkmark$ Maria ouviu falar que os detetives Marcelo e Luiz que trabalham no escritório Detetives da Água conseguiam resolver qualquer mistério. Como Maria estava muito preocupada com o mistério que havia em sua casa chamou os detetives para juda-la.

$\checkmark$ “Qual é o problema?". Perguntou Marcelo.

$\checkmark$ "Bem," disse Maria. "como você sabe eu alugo vários apartamentos para estudantes. Nunca deixei que mais que quatro estudantes ficassem em um apartamento. Acho, mas não posso provar que no apartamento 302 , estão morando mais que quatro pessoas."

$\checkmark$ "Você já fez visitas de surpresa?" Perguntou Luiz.

"Sim" Ela respondeu. "mas todas as vezes que vou lá tem quatro ou menos pessoas. Os estudantes entram e saem toda hora do dia e da noite. Eu não tenho como saber quantas pessoas moram em cada apartamento."

$\checkmark$ "Muito interessante," disse Luiz. "Nós podemos ajudar você, mas antes precisamos ver as últimas contas de água do apartamento 302."

$\checkmark$ "Como isto pode ajudar?" perguntou Maria.

"Nós poderemos saber quantos litros de água foram usados nos últimos meses." Disse Marcelo.

$\checkmark$ Maria achou a conta e Luiz e Marcelo descobriram que o apartamento 302 nos últimos meses gastou em media $20000 \mathrm{~L}$ por mês.

$\checkmark$ "Sim," disse Maria. "mas, isto é muito ou pouco?"

$\checkmark$ "Nós iremos investigar e voltamos. Vamos pesquisar quanto uma pessoa usa em média (deve haver uma unidade de tempo associada) por dia aqui em nossa cidade." Disse Luiz.

$\checkmark$ Os detetives prometeram a Maria que logo voltariam sabendo quantas pessoas moram no apartamento. Luiz e Marcelo concluíram que teriam que pesquisar quanta água, em média, uma pessoa usa por dia naquela cidade. $\mathrm{O}$ primeiro passo foi descobrir quanta água usavam as pessoas de suas próprias famílias (Tabela 1).

Tabela 1. Utilização média de água por pessoa e por dia

\begin{tabular}{l|c}
\hline Atividade & L/dia \\
\hline Banho & 45 \\
\hline Escovar os dentes & 12 \\
\hline Lavar o rosto & 3 \\
\hline Descarga & 15 \\
\hline Lavar louça & 15 \\
\hline Lavar roupa & 15 \\
\hline Beber & 2 \\
\hline Alimentos & 6 \\
\hline Limpeza da casa & 30 \\
\hline
\end{tabular}

Que respostas Luiz e Marcelo levaram para Maria? Como chegaram a esta conclusão?

\subsection{Atividade II - 0 ciclo da água}

Objetivos: Destacar alguns fatos relacionados ao ciclo da água. Trabalho em equipe. Revisão de conceitos.

Materiais recomendados: $\mathrm{O}$ caso do desaparecimento da água

Aspectos teóricos relacionados: As moléculas de água continuamente mudam de fase na natureza, esta circulação eterna constitui o chamado ciclo da 
água, que se relaciona ao conjunto das mudanças de lugar e de estado físico da água ao longo do tempo.

Neste ciclo, sob a ação dos ventos e dos raios solares, as águas dos rios, lagos e oceanos evaporam. A transpiração dos seres vivos também lança vapor na atmosfera. O vapor de água sobe e, ao encontrar as camadas mais frias da atmosfera, condensa-se e forma nuvens. As nuvens são compostas de uma grande quantidade de gotículas de água, que permanecem em suspensão na atmosfera. Estas gotículas, em certas condições, agregam-se formando gotas maiores que se precipitam, ou seja, chove.

Parte da água que cai no solo torna a evaporar. Outra parte escorre pela superfície, atingindo rios e mares. Certa quantidade de água se infiltra na terra e forma os lençóis de águas subterrâneas. Estes, por sua vez, acabam abastecendo rios, mares, lagos e fontes, fechando assim o ciclo.

\section{Atividades:}

- Pedir aos alunos que desenhem o ciclo da água.

- Recolher os desenhos e observar se ocorreram erros. (Muitos alunos esquecem a infiltração, é interessante observar este detalhe (Sabino et al. 2009))

- Explicar o ciclo da água chamando atenção para os aspectos esquecidos.

- Ler o texto "O caso do desaparecimento da água”.

- Pedir aos alunos que, em grupo, discutam e respondam a perguntas apresentada.

O caso do desaparecimento da água (Adaptado de Susan M. McMaster)

$\checkmark$ Os detetives Marcelo e Luiz, que trabalham no escritório Detetives da Água foram chamados à casa de D. Maria Flor. Quando lá chegaram, Francisco, filho de D. Maria Flor, estava muito nervoso. Sua mãe havia sumido! Os detetives perguntaram quando isto tinha acontecido.

$\checkmark$ "Este é um de meus problemas," disse Francisco. "Eu estava viajando e me esqueci de ligar para ela. Agora me sinto péssimo. Não sei onde ela está e nem há quanto tempo ela sumiu!"

$\checkmark \quad$ "Você sabe se ela pode ter ido a algum lugar onde costumava ir?" Perguntou o detetive Marcelo. $\checkmark$ Francisco franziu a testa demonstrando concentração. "Bem," disse ele, "os hábitos de mamãe são bem previsíveis”. Se ela sumiu há menos que um dia, ela foi fazer compras. "Se ela sumiu há menos que três dias, ela deve estar visitando a irmã, minha tia Felisberta, que mora numa cidade aqui perto."

$\checkmark \quad$ "Se ela sumiu há mais que três dias, mas menos que sete,", continuou Francisco, "deve ter comprado um pacote de viagem. Ela queria muito viajar." "Se ela sumiu há mais que sete dias, mas menos que seis semanas, provavelmente foi visitar Tio Carlos que mora no interior. Ela nunca se ausentou mais que seis semanas. Se isto aconteceu seres extraterrestres devem tê-la capturado e levado para outra galáxia. Ela ama sua casa e suas plantas e jamais as deixaria tanto tempo sozinhas."

$\checkmark \quad$ "Creio que vamos ajudar você a resolver o mistério." Disse Luiz que tinha examinado detalhadamente todos os cantos da casa.

$\checkmark$ "Você encontrou um bilhete dela?" Perguntou Francisco.

$\checkmark$ “Não." Disse Luiz. "Eu encontrei este copo graduado na janela.”.

$\checkmark$ “Oh” disse Francisco. "isto não é nada. Minha mãe é muito sistemática. Todas as manhãs ela enche o copo até a marca superior e deixa na janela para a água aquecer com o calor do sol antes de molhar suas queridas violetas. Ela é muito cuidadosa com a quantidade de água porque violetas não gostam de muita água.”

$\checkmark \quad$ "Aha". Disse Luiz. "Exatamente o que eu suspeitava. Vamos resolver o mistério. Veja agora só tem 3/4 do copo.”

"Você esta sugerindo que alguém roubou 1/4 da água de minha mãe?" perguntou Francisco.

$\checkmark \quad$ "Não me surpreende a mãe não lhe ter dito aonde ia." disse Marcelo sorrindo.

"Não Francisco." disse pacientemente Luiz, tentando não rir. "temos aqui um caso de evaporação. A água se evapora com o calor que vem do sol." 
$\checkmark \quad$ Vamos fazer um experimento. Vamos colocar um copo de água no mesmo lugar em que sua mãe colocou e vamos ver quanto tempo vai demorar a evaporar 1/4. "A partir do resultado vamos saber quanto tempo se passou desde que D. Maria Flor colocou o copo na janela e saiu de casa.”

$\checkmark$ "Que alívio!" disse Francisco. "Podemos saber agora?"

$\checkmark \quad$ "Ahfff" disse Luiz. "Por favor, saia daqui....Vai molhar as plantas, Francisco."

Explique aos alunos que eles serão detetives e vão desvendar um caso de desaparecimento.

\subsection{Atividade III - Lendas e mitos da água}

Objetivos: Destacar alguns fatos relacionados à presença da água na arte, lendas, religiões e mitos. Trabalho em equipe. Revisão de conceitos.

Materiais recomendados: Livros de História, Livros da Biblioteca, Internet.

Aspectos teóricos relacionados: Este forte elo está presente nas lendas e nas religiões (Alves 2005). Entre as mais antigas lendas de todos os povos estão a das sereias. Os marinheiros, nas primeiras expedições (quais expedições? de que época?), já temiam esses seres míticos.

A lenda das sereias apareceu pela primeira vez nas obras de Homero que, nas Odisséias, descreve criaturas que cantavam para seduzir e encantar marinheiros, conduzindo-os à morte. A associação das sereias com criaturas metade mulher, metade peixe, apareceu no século II AC (Chevalier 1991). A sereia mora nas águas do mar. Hans Christian Andersen eternizou a figura com a lenda da pequena sereia. Uma nova versão dessa lenda se tornou famosa a partir de 1989 quando os estúdios Disney lançaram o desenho "Pequena Sereia", baseado na história de Andersen.

No Brasil, mais precisamente no Amazonas, encontra-se a lenda da Mãe d'Água, que é a sereia das águas amazônicas. Dotada de indescritível beleza e canto maravilhoso, a Mãe d'Água encanta os pescadores que passam muito tempo sozinhos a navegar. Muitos deles não resistem ao seu delicioso canto e à sua beleza estonteante. Esses são levados pela Mãe d'Água para morar com ela nas profundezas das águas onde desaparecem. A maioria nunca mais volta para suas famílias. A Mãe d'Água habita as águas doces; rios e igarapés são os seus domínios
(Pinheiro 2003, Penna 2000).

Já nas religiões africanas, a deusa das águas é Iemanjá. Conta a tradição que, no início, tudo era fogo, chamas e vapores, formando tenebroso e cáustico universo onde habitava o solitário Olodumaré. Cansado de viver assim, este poderoso deus fez liberar com suas forças todas as águas, que jorraram pondo fim àquele triste e abrasador cenário.

Do que sobrou da inundação, fez-se a terra. E, nela, Olodumaré criou os orixás para habitarem e comandarem cada elemento desse novo mundo, em seu nome. O primeiro orixá a ser criado pelo deus, para com ele participar da criação dos demais, foi Iemanjá, a poderosa senhora das águas da Terra, a mãe de todos os seres viventes.

As lendas e mitos são muitos e diversificados, mas o que permanece sempre que se busca conhecer os enredos possíveis para a história de Iemanjá é sua relação com as grandes águas primordiais da terra, matriz de toda vida, e seu poder gerador e criador. Iemanjá é e sempre foi a grande mãe, a grande geratriz ioruba (Barros 2006).

No Brasil a história da Padroeira está também ligada às águas. Conta a tradição que, em 1717, três pescadores batalhavam no rio Paraíba, sem obter nenhum sucesso. O problema era que o governador da Capitania de São Paulo e Minas Gerais ia visitar Guaratinguetá e eles estavam incumbidos de providenciar a comida para toda a comitiva. Mas, não conseguiam pescar, os peixes não apareciam. Então um dos pescadores pescou em sua rede uma santinha de madeira mutilada. Mais adiante, a tarrafa trouxe a cabeça que faltava. Foi só encostar a cabeça no corpo da santa, para os peixes começarem a aparecer dentro das redes dos três. Foi sem dúvidas um milagre (diz a crença). Quem guardou a imagem e mandou seu filho fazer ermida foi Filipe Pedroso. Chegava gente de todas as cidades para ver a santa pretinha de 38 centímetros. Ficou famosa e fez tantos devotos que em 16 de julho de 1930, a pedido do clero brasileiro, o Papa Pio XI declarou Nossa Senhora Aparecida Padroeira Principal do Brasil. Grandes festas são também realizadas em homenagem a Nossa Senhora Aparecida (Penna 2000, Altemeyer 1998).

\section{Atividades:}

- Dividir a turma em pequenos grupos e pedir que cada grupo faça um trabalho de investigação sobre a presença da água na cultura, arte, folclore e religião em sua região.

- Peça aos alunos que façam entrevistas com 
pessoas da região a respeito do tema pesquisado no item anterior. Podem ser entrevistados artistas, líderes religiosos, pessoas que conheçam lendas e folclore, pessoas de outros lugares que tenham outras tradições e mais.

- Peça que os alunos escrevam relatórios e façam apresentações para os colegas sobre os resultados da pesquisa e das entrevistas.

- Faça em sala a atividade "O artista sou eu".

\section{0 artista sou eu}

- Explicar que os recursos naturais são importantes na formação das culturas e artes e que os artistas se inspiram por diferentes caminhos e uma obra de arte não apenas sensibiliza nosso sentido estético, mas também desperta nossa atenção para assuntos específicos. Como exemplo cantar, ou tocar uma música relacionada à água (Se algum aluno for músico pedir que ele faça a apresentação).

- Explicar o que é um símbolo. Apresentar alguns símbolos conhecidos em sua região, no Estado e no País.

- Se possível, pedir aos alunos que pesquisem símbolos na internet.

- Pedir que os alunos citem outros símbolos que conhecem. Motivar uma discussão com perguntas como: Por que símbolos são usados? Um símbolo é compreendido por todos? O que dificulta a compreensão de um símbolo?

- Dividir a turma em grupos de quatro alunos e pedir que façam desenho de um símbolo que represente a importância da água na cultura local.

- Preparar um painel com os desenhos e escolher (ou promover uma votação) o melhor.

- Premiar o melhor com um diploma e uma maçã, uma caneta, bombons ou outro prêmio.

\subsection{Atividade IV - A água no mundo}

Objetivos: Destacar alguns fatos relacionados aos conflitos devidos à água. Trabalho em equipe. Revisão de conceitos.

Materiais recomendados: Livros da Biblioteca, Internet.

Aspectos teóricos relacionados: Três quartos da superfície da Terra são recobertos por água.
Trata-se de quase 1,5 bilhões de $\mathrm{km}^{3}$ de água em todo o planeta, contando oceanos, rios, lagos, aquíferos e geleiras. Apesar de toda esta quantidade do precioso líquido, vinte e nove países já têm problemas com a falta d'água. Diversos conflitos relacionados à água estão ocorrendo no mundo e podem vir a piorar. (WHO, 2005)

$\mathrm{Na}$ China, por exemplo, o suprimento de água está no limite. A demanda agroindustrial e a população de 1,2 bilhões de habitantes fazem com que milhões de chineses andem quilômetros por dia para conseguir água. Mais de 12 milhões de chineses encontram-se sem acesso a água potável, após seca prolongada. A seca, no norte, noroeste e sudoeste do país, afeta, além dos milhões de pessoas, 14 milhões de hectares de terra arável e 11 milhões de cabeças de gado sofrem com a falta de água, especialmente o município de Chongqing e as províncias de Sichuan, Guizhou e Yunnan. (IOL diário, Portugal 2008).

Também na Índia, com uma população de 1 bilhão de habitantes, o governo indiano enfrenta o dilema da água constatando o esgotamento hídrico de seu principal curso d'água, o rio Ganges. (Agência Brasil 2007).

O jornal The New York Times publicou uma série de três reportagens sobre água na Índia, intitulada "Gigante Sedento". Depois de falar sobre a falta d'água nas cidades do país, conta que a retirada acelerada do recurso subterrâneo causa preocupação. Agricultores em crise estão deixando de plantar para se dedicar à exploração de mananciais que podem não durar muito. Alguns dos poços mais antigos já secaram. (Ministério da Educação e Cultura 2006).

A história recente do Oriente Médio não inspira grandes esperanças: a Guerra dos Seis Dias, em 1967, começou quando engenheiros sírios tentaram desviar parte do fluxo de água de Israel.

Após assinar o tratado de paz com o Estado israelense, em 1979, o presidente do Egito, Anwar Sadat, disse que seu país nunca mais lutaria em uma guerra, exceto para proteger suas fontes de água. $\mathrm{O}$ rei Hussein, da Jordânia, também já deu declarações neste sentido. (Folha online 2007)

A questão da água está sempre presente nas negociações de paz entre israelenses e palestinos, já que os aquíferos que abastecem Israel ficam na Cisjordânia e o rio Jordão corre por uma parte dos territórios ocupados.

O Oriente Médio é a região com menor disponibilidade de água por habitante: enquanto que 
$5 \%$ da população mundial vivem na área, ela conta com apenas $1 \%$ da água fresca existente no planeta. Países como Egito, Argélia e Marrocos gastam entre $20 \%$ e $30 \%$ de seus orçamentos em suprimentos de água.

No Norte da África, nos próximos 30 anos, a quantidade de água disponível por pessoa estará reduzida em $80 \%$. A região abrange países situados no deserto do Saara, como Argélia e Líbia.

Como declarou Bento XVI: "A sede mata os filhos da África". "Na África, morre uma criança a cada quinze segundos, porque não tem acesso à água potável e a seca está a agravar-se cada vez mais, especialmente no corno da África", revela o jornal do Vaticano. (PIME: Vaticano 2006)

O "Observatore Romano" cita ainda uma frase da homilia que o Sumo Pontífice pronunciou por ocasião do Corpus Christi (2006): "Num período em que se fala de desertificação e no qual ouvimos novamente a denúncia do perigo de que homens e animais morram de sede nessas regiões sem água, damo-nos conta, de novo, da grandeza do dom da água”.

Também a ONU alertou que o impacto devastador da seca nos países do Corno da África é inevitável para milhões de pessoas. O alerta dirigiu-se particularmente para a situação de 40 mil crianças, que correm risco de vida devido à má nutrição.

Nos cinco países que integram a região - Eritreia, Etiópia, Quênia, Somália e Djibuti - há 16 milhões de pessoas afetadas pela seca, das quais oito milhões precisam de ajuda de emergência e 1,6 milhões são crianças com menos de cinco anos. Entre as crianças, 300 mil estão muito mal alimentadas e 40 mil correm o risco de morrer. Oitenta por cento da população afetada são pastores nômades que cruzam as fronteiras da região várias vezes à procura de áreas de pasto e de água.

Quando o assunto é recursos hídricos, o Brasil é um país privilegiado. O território brasileiro detém $14 \%$ de toda a água doce superficial da Terra. A maior parte desse volume, cerca de $80 \%$, localiza-se na Amazônia e no Pantanal.

Numa região desabitada está a maior bacia fluvial do mundo, a Amazônica, com 6 milhões de quilômetros quadrados, abrangendo, além do Brasil, Bolívia, Peru, Equador e Colômbia. A segunda maior bacia hidrográfica do mundo, a Platina, também está parcialmente em território brasileiro.

Mas a nossa riqueza hídrica não se restringe às áreas superficiais: o aquífero Botucatu/Guarani, um dos maiores do mundo, cobre uma área subterrânea de quase 1,2 milhões de quilômetros quadrados, $70 \%$ dos quais se localiza em território brasileiro. O restante do potencial hídrico distribui-se de forma desigual pelo país. Apesar de tanta riqueza, as maiores concentrações urbanas encontram-se distantes dos grandes rios, como o São Francisco, o Paraná e o Amazonas.

Assim, dispor de grandes reservas hídricas não garante o abastecimento de água para toda a população. Além disso, os rios e lagos brasileiros vêm sendo comprometidos pela queda de qualidade da água disponível para captação e tratamento. Na região amazônica e no Pantanal, por exemplo, rios como o Madeira, o Cuiabá e o Paraguai já apresentam contaminação pelo mercúrio, metal utilizado no garimpo clandestino, e pelo uso de agrotóxicos nos campos de lavoura. Nas grandes cidades, esse comprometimento da qualidade é causado por despejos de esgotos domésticos e industriais, além do uso dos rios como convenientes transportadores de lixo.

\section{Atividade:}

- Discutir a distribuição da água na terra e no Brasil. Explicar que a água potável não é uniformemente distribuída causando problemas regionais e locais.

- Explicar o que é um plebiscito.

- Ler e discutir o dilema "Plebiscito em Monte Feliz".

- Pedir aos alunos que em grupos representem diferentes papéis relacionados ao problema. Dividir os alunos em grupos de: fazendeiros, pessoas idosas, pessoas pobres, pessoas ricas com piscinas nas casas. Pedir que discutam como estas pessoas irão reagir às opções do plebiscito.

- Solicitar que um representante de cada grupo exponha as opiniões do grupo.

- Em seguida discutir com os alunos qual será o provável resultado do plebiscito.

\section{Plebiscito em Monte Feliz}

Os fazendeiros de Monte Feliz têm um problema: Devido ao desperdício e à irrigação excessiva, as fontes de água estão secando. Para proteger a água que resta, a câmara de vereadores da cidade propôs um plebiscito para estabelecer uma nova política de conservação de água que fosse aceita pelos cidadãos. Depois de vários debates o seguinte panfleto foi distribuído Apresente o panfleto em uma cartolina conforme Figura 1. 


\section{De: Câmara dos vereadores}

Para: Cidadãos de Monte Feliz

Assunto: Escassez de água

A câmara dos vereadores de Monte Feliz decidiu adotar uma nova política em relação a água. Precisamos decidir entre:

A) Aumentar o preço da água para as pessoas usarem menos;

\section{$\mathrm{Ou}$}

B) Racionar a água (permitir que as pessoas, principalmente fazendeiros, usem uma quantidade determinada) evitando desperdício.

\section{Nós valorizamos seu voto!}

Venha à câmara dos vereadores na próxima quinta-feira para votar e nos dizer qual política devemos adotar.

A situação é crítica e algo tem que ser feito.

\section{A votação definitiva será daqui a duas semanas.}

Figura 1. Quadro extraído de panfleto do plebiscito em Monte Feliz

\subsection{Atividade V- Contaminação da água}

Objetivos: Destacar alguns fatos relacionados à contaminação da água. Trabalho em equipe. Revisão de conceitos.

Materiais recomendados: Livros da Biblioteca, Internet.

Aspectos teóricos relacionados: A contaminação da água por tóxicos ocorre em decorrência de diferentes atividades humanas. As diversas substâncias além de contaminar as águas superficiais, estão sujeitas à migração através do solo com consequente contaminação dos aquíferos. Exemplos de contaminações são frequentes na bibliografia desde tempos antigos até nossos dias (Allen 1993 , IGAM 2010).

A Organização Mundial de Saúde afirma que $80 \%$ da mortalidade infantil são devidos às doenças provocadas pela água. No Brasil, assim como em Minas Gerais, um dos principais contaminadores das águas são os esgotos, inclusive domésticos.

Entre os parâmetros que indicam essa conta- minação estão: a demanda bioquímica de oxigênio (DBO) e o teor de coliforme termo tolerante. A DBO é definida como a quantidade de oxigênio necessária para oxidar a matéria orgânica biodegradável em condições aeróbicas, isto é, avalia a quantidade de oxigênio dissolvido. Águas contaminadas por esgotos têm muita matéria orgânica e elevada DBO. A presença de um alto teor de matéria orgânica pode induzir à completa extinção do oxigênio na água, provocando o desaparecimento de peixes e outras formas de vida aquática. Um elevado valor da DBO pode indicar um incremento da microflora presente e interferir no equilíbrio da vida aquática, além de produzir sabores e odores.

A Portaria $n^{\circ} 357$ do Ministério do Meio Ambiente de 17 de março de 2005 que dispõe sobre a classificação dos corpos de água e diretrizes ambientais para seu enquadramento, também estabelece as condições e padrões de lançamento de efluentes estabelece que o valor máximo de DBO deve ser $10 \mathrm{mg} / \mathrm{L} \mathrm{O}_{2}$, como exemplo, no Rio das Velhas o valor alcança $186 \mathrm{mg} / \mathrm{L} \mathrm{O}_{2}$, ou seja quase 20 vezes acima do máximo permitido (IGAM 2010).

As bactérias do grupo coliforme são alguns dos principais indicadores de contaminações fecais, são originadas do trato intestinal humano e de outros animais. A determinação da concentração dos coliformes assume importância como parâmetro indicativo da possibilidade de existência de microrganismos patogênicos, responsáveis pela transmissão de doenças de veiculação hídrica, tais como febre tifoide, febre para tifoide, disenteria bacilar e cólera. As parasitoses intestinais constituem-se num grave problema de saúde pública, sobretudo nos países do terceiro mundo, sendo um dos principais fatores debilitantes da população, associando-se frequentemente a quadros de diarreia crônica e desnutrição, comprometendo, como consequência, o desenvolvimento físico e intelectual, particularmente das faixas etárias mais jovens da população (Nascimento 2005). A diminuição da incidência de parasitoses está relacionada ao fornecimento de água e saneamento básico. (Ludwig 1999).

De acordo com a Portaria anteriormente citada o limite máximo de coliforme termo tolerante é 2500 coliformes por $100 \mathrm{~mL}$. No Rio das Velhas o valor chega a ser 160000 coliformes por $100 \mathrm{~mL}$, ou seja, 64 vezes acima do máximo permitido. (IGAM 2010).

Minerações podem produzir rejeitos e contaminação devido à movimentação de minérios, processos de beneficiamento e explosões. Muitas 
vezes os rejeitos sólidos e/ou minérios são empilhados, sofrendo lixiviação (Pinto 2006). Entre os metais que contaminam a água podemos destacar o chumbo que é uma substância tóxica cumulativa produzindo uma intoxicação crônica que pode levar a uma doença denominada saturnismo. De acordo com a Portaria já citada o valor máximo permitido de chumbo em águas é $0,033 \mathrm{mg} / \mathrm{L}$; no Rio das Velhas (MG) o valor chega a $0,76 \mathrm{mg} / \mathrm{L}$, ou seja mais que 20 vezes acima do permitido (IGAM 2010). Vários outros contaminadores metálicos poderiam também ser citados como exemplos.

Acidentes devidos a transportes de materiais tóxicos ou combustíveis ocorrem frequentemente, apesar de toda a legislação relativa ao assunto. Em tais casos são necessárias medidas imediatas, equipe treinada e os resultados tendem a ser irreversíveis, por maiores que sejam os esforços de descontaminação. A principal evidência de contaminação por esses materiais é a ocorrência de derramamento. As causas são: acidentes, manutenção inadequada, falta de treinamento do pessoal envolvido, container não apropriado e procedimentos inadequados para descontaminação. (Corseuil 1997, Brito 2004). A contaminação de solos e águas por compostos orgânicos voláteis tem gerado grande problema ambiental nas últimas décadas. Uma das principais fontes de contaminação são os vazamentos de combustíveis dos postos de distribuição em função do envelhecimento dos tanques de estocagem. Os contaminadores podem ser: gasolina, óleos, graxas, ácidos e produtos corrosivos ou inflamáveis. O teor de óleos e graxas na água é um dos indicadores deste tipo de contaminação. Segundo a legislação, tais compostos devem estar ausentes, ou seja, a concentração deve ser $0,0 \mathrm{mg} / \mathrm{L}$ (ausente). No Rio das Velhas o valor chega a ser $18 \mathrm{mg} / \mathrm{L}$, o que é bastante elevado pois a presença de óleos e graxas diminui a área de contato entre a superfície da água e o ar atmosférico, impedindo a transferência do oxigênio da atmosfera para a água (IGAM 2008).

Produtos químicos são aplicados ao solo para controle de pragas, assim como para controle do crescimento e otimização das plantações. $\mathrm{O}$ uso desses produtos implica em risco de contaminação. (Ministério da Agricultura 2002). Agrotóxicos são largamente utilizados no Brasil e inúmeros são os casos de contaminação de alimentos e águas por esses produtos (Oliveira 2004, Gomes 2006, Lucena 2004).

Os fertilizantes, aplicados ao solo, contêm basicamente fósforo, potássio e nitrogênio (NPK).
Destes principalmente o nitrogênio implica riscos para o ambiente e para o homem. (Lucena 2004). A principal evidência de contaminação é o alto teor de fosfato e nitrato nos testes da água (Resende 2002). De acordo com a legislação o valor máximo de nitrato na água é $10 \mathrm{mg} / \mathrm{L}$ no Rio Doce o valor chega a ser $21 \mathrm{mg} / \mathrm{L}$. O valor máximo de fósforo permitido é $0,15 \mathrm{mg} / \mathrm{L}$. No Rio Grande, em Minas Gerais o valor chega a $9 \mathrm{mg} / \mathrm{L}$, ou seja, 60 vezes acima do permitido (IGAM 2010). Muitos outros exemplos poderiam ser citados sobre fontes de contaminação e as consequências dessas para as águas do Estado de Minas Gerais e de outros locais.

\section{Atividade}

Júri simulado

1. Preparar seis cartões, cada um para um dos personagens do júri simulado:

Cartão 1 - Dr. Saulo

Você é um cientista preocupado com a poluição que poderá ser gerada pelo aterro. Você não quer que seja na Fazenda do Seu João porque esta fica próxima ao rio. Você também não quer nas terras de D. Rosa, porque são próximas da cidade e o cheiro do aterro poderia alcançar os moradores. Você pensa que o aterro tem que ser construído na melhor opção que é a Florestinha do Riacho.

Cartão 2 - Alice de Souza

Você é a filha de 12 anos do Seu João. Você não quer que o aterro seja construído próximo de sua casa porque poderia ser prejudicial para a saúde de seus familiares. Por você o aterro pode ser construído em qualquer outro lugar.

Cartão 3 - Jorge Silva

Você é o motorista que dirige o caminhão da prefeitura que atualmente transporta o lixo para o lixão. Você conhece bem os custos do transporte do lixo e quer que o novo aterro seja construído nas terras de D. Rosa, que são mais próximas da cidade. A economia no custo do transporte do lixo poderia ser revertida na construção de um novo hospital na cidade.

\section{Cartão 4 - D. Margarida}

Você é uma senhora de 55 anos que possui terras próximas a Bela Vista que espera vender por um bom preço para se aposentar e realizar seu sonho de viajar pelo mundo.

\section{Cartão 5 - Geraldo Magela}

Você corta árvores na Florestinha do Riacho e vende a madeira para uma carvoaria local. Se o aterro for construído neste local você perderá o seu 
negócio. Você é de opinião que o aterro deve ser construído na Fazenda do Seu João.

Cartão 6 - Maria Aparecida Costa

Você é uma moça de 22 anos que trabalha no escritório do Geraldo Magela. Você tem medo de perder seu emprego se o aterro for construído na Florestinha do Riacho. Tem medo também que o cheiro alcance a cidade se o aterro for construído nas terras de D. Rosa.

2. Começar a atividade com as perguntas:

O que você joga no lixo de sua casa? Pra onde vai o lixo de nossa cidade? Quem decidiu o destino de nosso lixo? Como esta decisão foi tomada? Quais os fatores que influenciaram a decisão? (custo, distância, saúde das pessoas, área disponível e outros)

3. Explicar que a decisão sobre o destino do lixo da comunidade nunca é uma decisão fácil.

4. Dizer aos alunos que por algum tempo seremos criativos. Pedir para imaginar que somos cidadãos de uma linda cidade imaginária, chamada Bela Vista no Estado de Minas Gerais. Precisamos decidir onde será construído o aterro da cidade. Três locais estão disponíveis para a construção: as Terras de D. Rosa; a Fazenda do Seu João e a Florestinha do Riacho.

5. Dividir o quadro em três regiões e escrever em cada: Terras de D. Rosa; Fazenda do Seu João e Florestinha do Riacho. Em cada uma das regiões fazer duas colunas intituladas: Vantagens/Desvantagens. Peça aos alunos que preencham o quadro em seus cadernos.

Você (o professor) será o prefeito da cidade. Seis alunos devem ser escolhidos para representarem cada um dos personagens referentes aos cartões de opinião. Os outros alunos serão os cidadãos na assembleia da cidade e irão votar depois da apresentação dos argumentos dos personagens.

6. Distribuir os cartões de opinião para os alunos escolhidos e deixar que os personagens preparem seus discursos durante 10 ou $15 \mathrm{~min}$.

- Abrir solenemente a assembleia da cidade, explicar o motivo da reunião e ceder a palavra aos personagens. Enquanto eles defendem seus argumentos anotar no quadro as vantagens e desvantagens citadas para cada um dos locais.

- Após as apresentações promover uma discussão por aproximadamente $10 \mathrm{~min}$.

- Perguntar aos alunos se os personagens citaram as vantagens/desvantagens que eles haviam anotado em seus cadernos. Se necessário complete o quadro.
- Tentar obter maioria. Perguntar: Onde o aterro deve ser construído? Pode ser útil priorizar as vantagens e desvantagens apresentadas pelos alunos. (Por exemplo: É mais importante pensar nos custos da obra ou na saúde das pessoas?)

- Após a discussão pedir que os alunos votem no local onde deverá ser construído o aterro. Mesmo que não tenha sido alcançada a maioria, o local com maior número de votos será o escolhido.

- Explicar que esta é uma versão simplificada de como é selecionado o local para o aterro de uma cidade e que muitas vezes esta decisão demora anos.

- Uma discussão deve ser feita ao final sobre as emoções geradas.

2 Aplicação e avaliação das atividades.

As estratégias didático-pedagógicas apresentadas neste trabalho foram aplicadas para 52 professores do ensino médio de escolas públicas de Minas Gerais, que ao final das atividades puderam, sem se identificar, avalia-las através de questionário semiestruturado. Os resultados estão apresentados a seguir.

Questão 1 - As técnicas de ensino utilizadas podem ser utilizadas na sua sala de aula? Por que?

- 41 professores responderam que sim e 11 não. A Tabela 2 apresenta as justificativas para as respostas dos professores para a Questão 1.

A maioria dos professores é favorável às atividades propostas, o que sugere, segundo Longo (2012), que muitos professores reconhecem a importância de utilizar metodologias diferenciadas de ensino na sua prática pedagógica. Vale salientar que a aprovação não reflete simplesmente a valorização do novo ou do variado, mas também a qualidade dos conteúdos e das práticas desenvolvidas. O professor compreende a necessidade de mudança e inovação na prática docente, com a utilização de atividades e jogos que proporcionem a mobilização dos conhecimentos, valores e atitudes de forma integrada diante da necessidade da sociedade contemporânea, mas normalmente reclamam não ter sido capacitados ou estimulados para isso.

Atendendo a sugestão de dois professores, os objetivos foram reformulados antes de disponibilizar o material no ambiente virtual.

Questão 2 - As atividades apresentadas foram capazes de estimular uma mudança em sua prática docente? 
Tabela 2. Justificativas dos professores para a Questão 1

\begin{tabular}{l|l|c}
\hline Respostas & Justificativas & $\mathbf{N}$ \\
\hline Positivas & Fáceis de aplicar & 10 \\
\hline & Atraentes e envolventes & 5 \\
\hline & Motivadoras & 3 \\
\hline & Interessante & 2 \\
\hline & Adequadas & 3 \\
\hline & Concentração & 2 \\
\hline & Dinâmica & 11 \\
\hline & Outras: competitivas, interativas, claras, lúdicas, turmas cheias, & 4 \\
\hline & simples, práticas, etc. & 2 \\
\hline & O material não pode ser comprado & 2 \\
\hline & Melhorar a descrição dos objetivos & 1 \\
\hline & Turma cheia & 1 \\
\hline & Barulho & 1 \\
\hline & Infantis de recurso & \\
\hline
\end{tabular}

49 professores responderam que sim e 3 não. A Tabela 3 apresenta as justificativas para as respostas dos professores para a Questão 2.

As respostas e justificativas indicam que maioria dos professores se sentiu motivada para a utilização dos conteúdos e atividades apresentadas. Não se justifica a resposta do professor que diz não saber onde encontrar estas técnicas uma vez que as mesmas foram disponibilizadas no livro "Água de beber, água de viver", disponível em: http://aguadeviver. wix.com/inicio .

Alguns professores comentaram que as atividades despertam a criatividade, segundo Paulo Freire
(1996) neste ponto entra o jogo, um recurso didático estimulador da criatividade, um facilitador da assimilação do conteúdo, pois através dele o aluno é agente da própria aprendizagem. É preciso acabar com o aprendizado da dependência, vamos resgatar nossa capacidade de trabalhar, de imaginar e de construir alternativas. Segundo Oliveira (2010), para fugir da rotina na sala de aula ou para despertar o interesse dos alunos em determinados conteúdos é necessário que o professor use a criatividade, busque metodologias distintas das que usualmente utiliza em sala de aula.

Com a mudança de comportamento dos alunos

Tabela 3. Justificativas dos professores para a Questão 2

\begin{tabular}{|c|c|c|}
\hline Respostas & Justificativas & $\mathbf{N}$ \\
\hline \multirow[t]{8}{*}{ Positivas } & Conciliou teoria e prática & 9 \\
\hline & Acrescentou conhecimento & 6 \\
\hline & Novidade & 6 \\
\hline & Jogos interessantes & 5 \\
\hline & Técnicas diferentes & 5 \\
\hline & Criatividade & 5 \\
\hline & Prazeroso & 4 \\
\hline & $\begin{array}{l}\text { Outros: Práticas excelentes, melhorias na aprendizagem, simples, } \\
\text { motivadoras, maior interação, grande diversidade, etc. }\end{array}$ & 9 \\
\hline \multirow[t]{3}{*}{ Negativas } & Não sabe onde encontrar estas técnicas & 1 \\
\hline & Sem novidades & 1 \\
\hline & Esperava mais & 1 \\
\hline
\end{tabular}


Tabela 4. Justificativas dos professores para a Questão 3

\begin{tabular}{l|c|c}
\hline Respostas & Justificativas & N \\
\hline Positivas & Podem ser utilizadas no dia a dia & 17 \\
\hline & Bem direcionadas & 12 \\
\hline & Atraentes & 10 \\
\hline & Outros - atenção na aprendizagem, desenvolve senso crítico, novas perspectivas, & 10 \\
& conceitos claros, etc. & 2 \\
\hline Negativas & As escolas são falhas & 1 \\
\hline
\end{tabular}

e com os diversos recursos que lhe são oferecidos dia-a-dia dentro da sociedade, estes estão cada vez mais ativos, necessitando que o professor mude a sua prática docente no sentido de estimular nos alunos o desejo de aprender, de entender, e de criticar com qualidade. Para que se tenha um verdadeiro, mais completo e significativo, aprendizado é preciso que um estímulo seja oferecido a este aluno com a utilização de um recurso pedagógico diferenciado (Macedo 2000).

Mediante o uso dos jogos e atividades como recursos didáticos, vários objetivos podem ser atingidos, relacionados à cognição (desenvolvimento da inteligência e da personalidade, fundamentais para a construção de conhecimentos); afeição (desenvolvimento da sensibilidade e da estima e atuação no sentido de estreitar laços de amizade e afetividade), socialização (simulação de vida em grupo); motivação (envolvimento da ação, do desafio e mobilização da curiosidade) e criatividade. (Macedo 2006).

Questão 3 - A utilização de ferramentas alternativas contribui para o melhor desempenho do processo ensino aprendizagem?

- 49 professores responderam que sim e 3 não. A Tabela 4 apresenta as justificativas dos professores para as respostas à Questão 3.

Muitos professores reconhecem que as atividades sugeridas podem ser facilmente desenvolvidas em suas escolas e destacando seu direcionamento, que aqui lemos como organização e simplicidade metodológica e de materiais. Destacam que as mesmas apresentam situações e conteúdos capazes de atrais a atenção e a afeição dos alunos.

Não é para nós, que trabalhamos com pesquisa em ensino, a reclamação de um dos professores sobre a dificuldade da aplicação de metodologias alternativas em sala com muitos alunos. Realmente esta pode ser uma dificuldade a ser contornada pelo professor. Sugerimos novamente que caso não seja possível aplicar as técnicas sugeridas o professor deve ser incentivado a utilizar alternativas ou adaptações para a execução das práticas sugeridas. O processo de ensino verdadeiramente pedagógico precisa de recursos diversificados presentes na nova realidade do mundo contemporâneo. Os docentes precisam se aprimorar, priorizar a capacidade produtiva, fazendo algo para recriar e resgatar a "vontade" de aprender de seus alunos. (Vigotski 1998).

Questão 4 - Citar pontos positivos das técnicas apresentadas segundo os Professores do REM (Tab. 5)

Para a maioria dos professores a oportunidade de trabalhar em equipe é o principal ponto positivo. Vale salientar que os jogos e as atividades coletivas proporcionam uma aula dinâmica, despertando o interesse do aluno para buscar o conhecimento, se envolver, trabalhar com regras que devem ser seguidas e se sentirem motivados para o trabalho

Tabela 5. Respostas dos professores para a Questão 4

\begin{tabular}{l|c}
\hline Respostas & N \\
\hline Interação entre todos & 11 \\
\hline Melhorar a aprendizagem & 7 \\
\hline Concentração & 5 \\
\hline Criatividade & 4 \\
\hline Atrativa & 3 \\
\hline Dinâmica & 3 \\
\hline Atenção & 2 \\
\hline Participação & 2 \\
\hline Socialização & 2 \\
\hline Prática inovadora & 2 \\
\hline Adequada & 2 \\
\hline $\begin{array}{l}\text { Outros: reforça conteúdo, } \\
\text { competição, trabalho } \\
\text { em grupo, compartilhar } \\
\text { conhecimento, uso de } \\
\text { vídeos, desmistificação } \\
\text { de aulas formais, jogos, } \\
\text { lúdico, etc. }\end{array}$ & \\
\hline
\end{tabular}


Tabela 5. Respostas dos professores para a Questão 5; apenas 13 professores citaram pontos a ser melhorados

\begin{tabular}{l|c}
\hline Respostas & $\mathbf{N}$ \\
\hline Disponibilizar o material & 2 \\
\hline Justificar os objetivos & 2 \\
\hline Fazer mais atividades & 2 \\
\hline Precisa de maior volume de informações & 2 \\
\hline Mais tempo para oficinas & 2 \\
\hline $\begin{array}{l}\text { Outros: utilizar ferramentas virtuais, tumulto, não focar no conteúdo mas no método, mais práticas, mais } \\
\text { música, organizar melhor o tempo, etc. }\end{array}$ & 3
\end{tabular}

em equipe. Segundo Lima et al. (2009), o jogo e as atividades educativas coletivas possibilitam resgatar a autoestima e a autoconfiança do aluno, bem como estreitar os laços de confiança entre ele e o professor, e também entre ele e os colegas.

Questão 5-Quais os pontos a serem melhorados segundo os professores do REM REM (Tab. 5)

As sugestões passíveis de aceitação foram consideradas e otimizadas. Outros comentários, como o que considerou tumulto, não foram infelizmente consideradas; o que é tumulto para uma pessoa pode ser alegria e/ou participação para outra.

Dois professores solicitaram mais atividades, o que é interessante, pois o professor que constantemente diversifica a sua metodologia estará atendendo a necessidade de seus alunos, desenvolvendo a autonomia e estimulando a comunicação, a criatividade e o desejo de aprender (Cardim 2001).

\section{Conclusões}

Todas as atividades humanas, em algum grau, interferem no meio ambiente. Materiais tóxicos e prejudiciais à vida são utilizados em diversas áreas, como indústria, saúde, química, agricultura e muitas outras. O desenvolvimento e a tecnologia são irreversíveis e estudos devem ser feitos para diminuir, prevenir e remediar os efeitos desses materiais na natureza e no homem.

A água está relacionada à vida e o comprometimento da qualidade das águas pode implicar mudanças nos ecossistemas e extinção de espécies. De fato, uma só pessoa geralmente pode fazer pouco para reverter o impacto ambiental negativo. $\mathrm{O}$ que cada um e todos podem fazer é procurar criar uma nova consciência e cultura de respeito ao ambiente, incluindo a água. É possível resgatar o sentimento instintivo de amor pela água que está mascarado pelas adversidades da vida moderna. Conviver com a natureza de forma harmônica e saudável facilita a paz e a felicidade. Por outro lado, condições de conflito e guerra são acompanhadas da degradação ambiental. Geralmente onde há um problema ambiental há também um problema social.

Apesar de todo o impacto que causamos ao meio ambiente com certeza a natureza irá se recuperar só não se sabe se a espécie humana estará aqui para presenciar. Se estaremos aqui para ver, depende também de nós e esta é uma decisão sobre a qual todos temos que pensar.

Sabemos que só protegemos o que conhecemos. Nesse sentido, conscientizar e esclarecer sobre os problemas ambientais são ferramentas poderosas para a formação da cidadania e melhoria da sociedade e do meio ambiente. Tornar esta aprendizagem interessante e prazerosa e significativa facilita alcançar tais objetivos. Concluímos que atividades como as propostas podem facilitar a tarefa dos professores contribuindo não somente para o ensino-aprendizado mas também para a formação e inserção social dos alunos.

\section{Agradecimentos}

Agradecemos à Secretaria de Educação do Estado de Minas Gerais, à FAPEMIG e a PUC Minas o financiamento e a oportunidade de trabalhar neste tema. Agradecemos também aos revisores de Terrae Didatica pelas sugestões para a versão final deste artigo.

\section{Referências bibliográficas}

Agência Brasil, EBC. 2007. Agência Brasil de comunicação. Falta de água deve afetar mais de um bilhão de pessoas em 20 anos. URL: http://www. agenciabrasil.gov.br/noticias/2007/02/15/materia.2007-02-15.9552793296/view. Acesso 4.12.2008. 
Allen H.E, Perdue E.M, Brown D.S. 1993. Metals in groundwater. Chelsea: Lewis Publishers. 249p.

Altemeyer F., Cordeiro J. 1998. Aparecida: os caminhos da fé. São Paulo: Ed. Loyola. 116p.

Alves C. 1997. Tubulação equivale a meia volta na Terra. São Paulo, Folha de São Paulo, p. 3-4, Ed. Nacional, 14 jun. (Cotidiano, Editorial).

Barros C.A . 1996. Iemanjá e Pomba Gira: Imagens do feminino na Umbanda. Minas Gerais. Juiz de Fora: Univ. Fed. Juiz de Fora. 104p. (Dissert. Mestrado).

Borba R.P., Figueiredo B.R., Cavalcanti J.A. 2004. Arsênio na água subterrânea em Ouro Preto e Mariana, Quadrilátero Ferrífero (MG). REM Rev. Esc. Minas. 57(1):45-51.

Brito F.V. 2004. Estudo da Contaminação de Águas Subterrâneas por BTEX oriundas de postos de distribuição no Brasil. In: Congr. Bras. P\&D em Petróleo e Gás, 3, 2004. Anais... Rio de Janeiro: Inst. Bras. Petróleo e Gás, IBP.

Brougere G. 1998. Jogo e Educação. Porto Alegre: Artes Médicas. 218p.

Cardim C.G. 2001. Aprender com os jogos e situações problema. Rev. Assoc. Bras. Psicopedag., 57:111-113.

Chevalier J., Gheerbrant A . 1991. Dicionário de Símbolos. Rio de Janeiro: José Olympio. 1040p.

Corseuil H.X., Marins M., Dal M. 1997. Contaminação de águas subterrâneas por derramamentos de gasolina: o problema é grave? Rev. Eng. Sanit. e Amb., 2(2):50-54.

Cunha M. B. 2012. Jogos no ensino de Química: Considerações Teóricas para sua utilização em sala de aula. Química Nova na Escola. 34(2):92-98.

Dansereau P. 1999. Ecologia humana, ética e educação. Florianópolis: Pallotti/APED. 700p.

Folha online. s.d. Oferta de água no Oriente Médio pode cair pela metade até 2050, diz BIRD. URL: http://www1.folha.uol.com.br/folha/bbc/ult272u61667.shtml. Acesso 12.08.2014.

Freire P. 1996. Pedagogia da autonomia: saberes necessários à prática educativa. São Paulo: Paz e Terra. 54p.

Gomes M.A.F., Spadotto C.A., Pereira A.S. 2006. Movement of the tebuthiuron herbicide in two representative soils of recharge areas of the Guarani aquifer. Rev. Bras. Eng. Agríc. Ambient., 10(2):479-483.

Instituto Mineiro de Gestão das Águas. 2005. Relatório de Implantação da rede de Monitoramento das Águas Subterrâneas das Sub-bacias dos Rios Verde Grande, Riachão e Jequitaí na Bacia do Rio São Francisco, em Minas Gerais. URL: http://www.igam.mg.gov. br/. Acesso 12.08.2014.

Instituto Mineiro de Gestão das Águas. 2010. Relatório de monitoramento das águas superficiais. URL: http:// www.igam.mg.gov.br/. Acesso 12.08.2014.

IOL Diário Portugal. Seca deixa milhões de chineses sem água potável. URL: http://diario.iol.pt/noticias/seca-alteracoes-china-clima-ambienteagua/797302-291.html. Acesso em 12.08.2014.

Kishimoto T.M. org. 2007. Jogo, brinquedo, brincadeira e a educação. 10 ed. São Paulo: Cortez Ed. 183p.

Lima M.C.F., Silva V. Valéria S., Silva M. E. L. 2009. Jogos educativos no âmbito educacional: um estudo sobre o uso dos jogos no Projeto Mais da Rede Municipal do Recife, URL: http: www. ufpe.br/ce/imagens/graduacao_pedagogia/pdf.. Acesso: 12.08.2014.

Longo V.C.C. 2012. Vamos jogar? Jogos como recursos didáticos no Ensino de Ciências e Biologia. URL: http://www.fcc.org.br/pesquisa/jsp/premioincentivoEnsino/arquivo/textos/textosFCC 35 Vera_Carolina_Longo.pdf. Acesso 12.08.2014.

Lucena L.R.F., Rosa F.E.F., Bittencourt V.L., Montaño J.X. 2004. A migração de constituintes iônicos no aqüífero barreiras na região sul de Natal-RN, decorrente do quadro estrutural local: uma hipótese de trabalho. Rev. Lat.-Amer. Hidrogeol., 4:9-16.

Ludwig K.M., Alvares F., Paes J.T.R. 1999. Correlação entre condições de saneamento básico e parasitoses intestinais na população de Assis, Estado de São Paulo. Rev. Soc. Bras. Medic. Trop., 32(5):547-555.

Macedo L.de, Petty A.L. 2000. Aprender com jogos e situações problema. Porto Alegre: Artmed. 106p.

Macedo L.de. 2005. Ensaios pedagógicos: Como construir uma escola para todos? Porto Alegre: Artmed. $167 \mathrm{p}$.

Macedo L.de, Machado N.J.M. 2006. Jogo e projetos: pontos e contrapontos. São Paulo: Summus. 141p.

Maslow A.H. 1979. Uma teoria de motivação humana. In: Balcão Y.F., Cordeiro L.L. 1979. O comportamento humano na empresa: uma antologia. 4 ed. Rio de Janeiro: FGV. 464p.

Ministério da Agricultura, Pecuária e Abastecimento. 2002. Agricultura e qualidade da água: contaminação pelo nitrato. ISSN 1517-5111. URL: http://www. agricultura.gov.br/. Acesso: 12.08.2014.

Ministério da Educação e Cultura. s.d. Seca profunda na Índia. URL: http://lba.inpa.gov.br/lba/ lba_ingles $/ ? \mathrm{p}=18 \& \lg =$ eng\&op $=850$. Acesso 12.08.2014.

Nascimento S. A. M., Barbosa J. S.F. 2005. Qualidade da água do aquífero freático no alto cristalino. Rev. Bras. Geoc., 35(4):543-550.

Oliveira L.M.S., Silva O.G., Ferreira U.V.S. 2010. Desenvolvendo jogos didáticos para o ensino de química. Holos, 26(5):166-175.

Oliveira S., Pasqual. 2004. Evaluation of indicative parameters of pollution for liquid effluent of a sanitary landfill. Eng. Sanit. Ambient. 9(3):240-249.

Oliveira L., A., Campos J. E. G. 2004. Parâmetros hidrogeológicos do sistema aqüífero Bauru na região de Araguari/MG:fundamentos para a gestão 
do sistema de abastecimento de água. Rev. Bras. Geoc., 34(2):213-218.

Penna L.C.A. 2000. Senhora das Águas na Amazônia. Rev. Junguiana, 18:18-29.

PIME: Vaticano. 2008. Água. URL: http://www.pime. org.br/noticias2006/noticiasvaticano240.htm. Acesso 12.08.2014.

Pinheiro X. J. 2003. Folclore. Gerir, 9(32).

Pinto P. C. 2006. Avaliação das condições ambientais na mineração em subsolo. REM Rev. Esc. Minas. 59(3):311-316.

Porto R.L. 1991. Hidrologia Ambiental. São Paulo: EDUSP. 414p.

PROCOM. 2002. Como ler a conta de água. URL: http://www.procon.sp.gov.br/pdf/consumidorconsciente07.pdf. Acesso 12.08.2014.

Resende V.A 2002. Agricultura e qualidade da água: contaminação da água por nitrato. Embrapa.

Ríos E., Solbes J. 2007. Las relaciones CTSA en la ensenãnza de la tecnologia y las ciencias: una propuesta con resultados. Rev. Electr. Enseñanza de las
Ciencias, 6(1):32-55.

Sabino C.V.S., Lobato W., Coutinho F., Ataide A.C.Z., Bueno A.P. 2009. Concepções de futuros professores sobre águas subterrâneas. Ensaio: Pesq. Educ. Ciências, 11:109-123.

SEEMG. 2013. Reinventando o ensino médio. URL: http://www.educacao.mg.gov.br/images/stories/publicacoes/reinventado_ensino_Medio_ WEB.pdf. Acesso 12.08.2014.

Venancio S., Freire J.B. 2005. O jogo dentro e fora da escola. Campinas: Papirus. 187p.

Vigotsk, L.S. 1998. A formação social da mente. São Paulo: Martins Fontes. 90p.

World Health Organization. 2005. Water For life: making it happens. WHO Library Cataloguing-inPublication Data WHO/UNICEF Joint Monitoring Programme for Water. ISBN 924156293 5. URL: http://www.who.int/water_sanitation_health/ monitoring/jmp2005/en/. Ácesso 12.08.2014.

Wilson E.O. 1984. Biophilia. Cambridge: Harvard Univ. Press.416p. 